\title{
Forms in Acquisitions Work
}

Mr. Sweet is acquisitions librarian, Cornell University Library.

$\mathrm{T}$ HE DESIGN and use of forms in library acquisitions work is conditioned by two basic factors:

( I) The interacting characteristics of size, organization, policies and methods, peculiar to the particular library or library system. For example: the organizational plan of the library determines, to a certain extent, which kinds of record-files are essential and which may safely be disregarded-alphabetical order-files, chronological order-files, or orderfiles arranged by source of supply, ordersreceived or accession files, fiscal or "fund" files, "in-process" files, etc.; and the types of records kept affect, in turn, the number and kinds of forms required. Similarly, volume of business-a function of size-exerts a considerable influence on the forms problem.

(2) The nature and frequency of operations involved in acquisitions routines, in general. Thus, the order department of every library is faced with certain basic problems: the solicitation of quotations, orderplacement, order-claiming or "follow-up," order-cancellation, the payment or approval for payment of invoices, etc.

The first of these factors makes for diversity, both in kinds of forms employed and in design within the same type of form; the second criterion, dispassionately considered and explored, argues for similarity and standardization. Since libraries and librarians tend to be so rampantly individual, the former, differentiating ingredient has all the best of it, and acquisitions forms in American libraries are far more remarkable for their, variety than for their uniformity. The order itself, for instance, may be a. letter-size order-sheet in duplicate or triplicate, or it may be the $3^{\prime \prime}$ x 5", multiple-copy, "correlated" orderslip; and among any broad collection of samples of the latter sort will be found variations: (a) in number of parts (from three or four to as many as nine), (b) in the disposition made of, and the names given to, those parts, (c) in the amount and kinds of information intended to be included on them, and the arrangement of that information on the slips, (d) in the use of one- or two-color printing, and of printing on one or both sides, and so on.

Admitting that part of this great diversity is the necessary consequence of institutional differences in size, set-up, and services undertaken, another large part merely reflects the librarian's lack of acquaintance with (or indifference to?) what other libraries are doing, and the absence of any real data as to what forms and methods are best, and why. To cite only one of many such needs: Have we any facts or figures to show that the use of a copy of the multiple-order-slip for "initial claiming" is either more or less effective and efficient than the use of a separate, speciallydesigned, claim form?

Apart from this not always necessary or desirable disengagement, there are other failings to which the library forms-designer is subject. One of these is a conservative resistance to change. The desirability and design of a form is apt to be carefully considered at the time of its initial adoption; and thereafter, nothing less than a change in department head (or higher echelon) can achieve its elimination, or even modification. Another is the tendency towards proliferation of sub-species and sub-sub-species. Once a form is adopted for the average book order, a separate style is developed for serials orders, and another variety for ordering material on approval, and still another for orders in response to quotations received, etc. A third failing is that of regarding the form as suitable only for the most routine, everyday functions. Far too often, the personal letter is used for a purpose which might be served just as effectively-and much more efficiently -by a form.

It must be true of other research libraries -as I know it is of ours-that the demands made upon them to handle an ever- and 
rapidly-increasing volume of business and number of services with a much-less-actively (at most times, imperceptibly) expanding staff create an exceptional pressure to make the most effective possible use of forms in streamlining and simplifying procedures. To facilitate that more- or most-effective use of forms, two desiderata are indicated: First, a periodic -at least annual-reexamination of the problem of forms in any given library, to consider which can be consolidated or eliminated, how existing forms may desirably be modified, and what situations recur with sufficient frequency to warrant the introduction of new forms. Secondly, the creation of more systematic and extensive channels than now exist for the dissemination of information between libraries as to the practices prevailing in other, similar institutions.

The following comments on three fairly broad and common problems, and some forms designed to meet them which exemplify what may be called the "synthetic trend," are offered as a merely suggestive and illustrative step in this latter direction.

I. Claiming, which means, in its narrow sense and common usage, the "follow-up" of overdue orders, is a problem recognized by every order department, and one for which an amazing variety of forms have been developed. The more common types are: printed postcard, with or without pre-addressed replycard attached; copy of "correlated" order-slip, with provision for vendor's reply on verso; printed or mimeographed half- or full-sheet form-letter. In part, this variation is due to the influence on the form-design problem both of the type of order-form used and of the claiming policy followed.

Claiming may be either systematic or selective: In the former instance, every order outstanding for more than a certain length of time is automatically claimed at the expiration of that period of grace; in the latter case, the onus is placed on the person who is waiting for the book-faculty member, departmental librarian, or other "customer"- to initiate the follow-up if the item fails to make its appearance in due course, and only those orders so questioned are claimed. Systematic claiming is certainly preferable; but selective claiming may be as much as over-all work pressures will allow-and, presumably, it serves to produce the more urgently required items. There can also be a combination of the two: selective claiming of the slightly overdue orders, and systematic claiming of the proportionately fewer orders long outstanding. Whichever policy is followed, systematic or selective, claiming may also be either persistent (repeated) or unique (one time only).

In libraries, such as those of Chicago and Columbia Universities, where the correlated order-slip is used and a systematic claiming policy is practiced, each set of order-slips includes its "claim copy" to be used for "first" claiming, in addition to the copy "to be returned with the book." In the General Library of the University of California, where I.B.M. cards are used as order-forms, a form "frame" is placed around the file copy of the order, and a micro-photostat is taken of the whole which serves as their claim form. At the University of Illinois Library, where a combination of McBee "Keysort" card for basic record and an order-sheet in triplicate is employed, a post-card claim form is used, with reply-card attached.

Apart from the design of the claim-form itself, other forms problems arise from these differences in follow-up procedures. Where the selective claiming expedient is used, it is advisable to have some sort of form, both for the use of the order-initiator in getting the claim proceedings started, and of the acquisitions department in reporting back the action actually taken. If persistent claiming is practiced, there must be some form device for regulating and recording the successive action taken and the results (if any). At Columbia, where a systematic-persistent policy obtains, a $34^{1 "} \times 5^{\prime \prime}$ "signal" card is used for that purpose: attached to the copy of the correlated order form in "Order Processing File," the $1^{1}$ " visible edge of the card shows when the next round of action is due, and there is provision on the verso for recording the date of each successive claim and the report received in reply.

Although such follow-ups on overdue orders represent the largest part of the claims to be made, it is a mistake to assume-as most libraries seem to do-that they are all there is to "claiming." In its broader sense, claiming means: the adjustment of any one in the complex of all the "hitches" which may occur, and in fact do recur with any degree of frequency, to prevent the prompt and satisfactory 
completion of an order transaction. In this sense, at least nine distinct claim situations may be identified:

(x) Shipment is overdue and unreported; claim shipment or report.

(2) Shipment has been received, but invoice is not with it, and does not follow promptly; claim invoice.

(3) Invoice is received, but shipment does not follow promptly; claim new shipment, or request tracer on first mailing.

(4) Wrong title, or edition, or volume is supplied; claim corrected shipment, and advise that incorrect item is being returned.

(5) Partial and incomplete shipment is received, without accompanying explanation; claim balance of order or report.

(6) Duplicate shipment of a single order is received; claim adjustment of vendor's records, and advise that second shipment is being returned.

(7) Defective copy is received; claim perfect, replacement copy, and advise that defective copy is being returned.

(8) Error is made in billing; claim corrected

"Sample \# I."

CORNELL UNIVERSITY LIBRARY THCA NTE YOAK

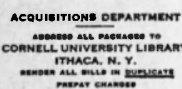
NEW YORK

With reference to our order no. dated for

please take immediate action on the matter(s) indicated by checkmark(s) be low:

Shipment not yet received; overdue; kindly send at once, or report. ipment received, but we lack invoice: send at once, in duplicate. or advise us promptly if no charge is due

error has been made in shipment: you have sent the following : which we are returning under separate cover. Please credit, and ship promptly the correct item. as indicated above.

Shipment, as received, is incomplets: you have billed us for but this was not received in the shipment containing other items on same invoice: please ship item promptly, or advise have received duplicate shipment of this order; first copy was arrived: this latter copy is therefore being returned to you under separate cover; in case of double charge. please credit. We find that the copy you have supplied is defective. as follows: ing returned under separate cover; please ship replacement copy promptly, on a "no charge." exchange basis.

We believe that an error has been made in billing: item has been

charged at $r$ ather than Other

Additional data invoice, or credit, or report, or advise that deduction is being made.

(9) Item is shipped in disregard of order terms or instructions (such as: request for report-before-shipment on society, series, or reprint publications) ; claim cancellation of charge, and advise that item is being returned.

Insofar as acquisitions librarians have recognized any other than the first of these as a form-worthy situation, they have tended to make a separate form for each. The synthetic approach would suggest their incorporation in a single, multiple-purpose, letter-size claim form. At Cornell, seven of the above nine situations have been provided for in a letter form of this sort, reproduced here as "Sample \# I." This form letter is designed for use in a window envelope, and is multilithed in approximately one-thousand-copy lots by the card-duplication section of our own catalog department. Appearance is good; cost is moderate; work of preparation is re-

"Sample \# 2."

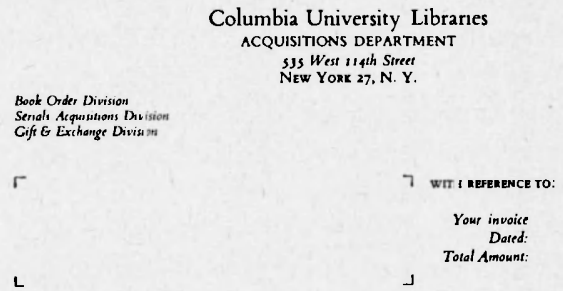

YOUR PROMPT attention to the incssage indicated below will help us to keep our acquisitions program on a current basis, and will be deeply appreciated.

SUDjECT: Our Order Number

OUR Messace:

We have received from yen the ilem (s) described above

W We have not as yet received an invoice for this material. Would you kindly supply a criplicate invoice on the enclosed forms at your earlest convenience? Please return this letter with your

$\square$ We can find no record of having placed an order with you for this material. Please supply u with our order number and date of order, of with any other information which will help us to identify our order. We will hold your invoice and material unetl we hear from you

$\square$ We have not yet received this material. Please inform us when and how it was shipped and if appropriate, institute tracer proceedings and inform us of your findings:

$\square$ According to our secords, we approved payment for the above-cired item on your earlier invoice of dated in the amount of

$\square$ We are approving payment for other items on the invoice, but are making a deduction for this one item.

$\square$ We ate returning your invoice with this letre

COLUMBIA UNIVERSITY LIBRARIES Acquisitions Department

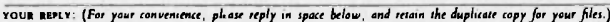

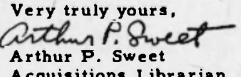

Arthur P. Sweet 

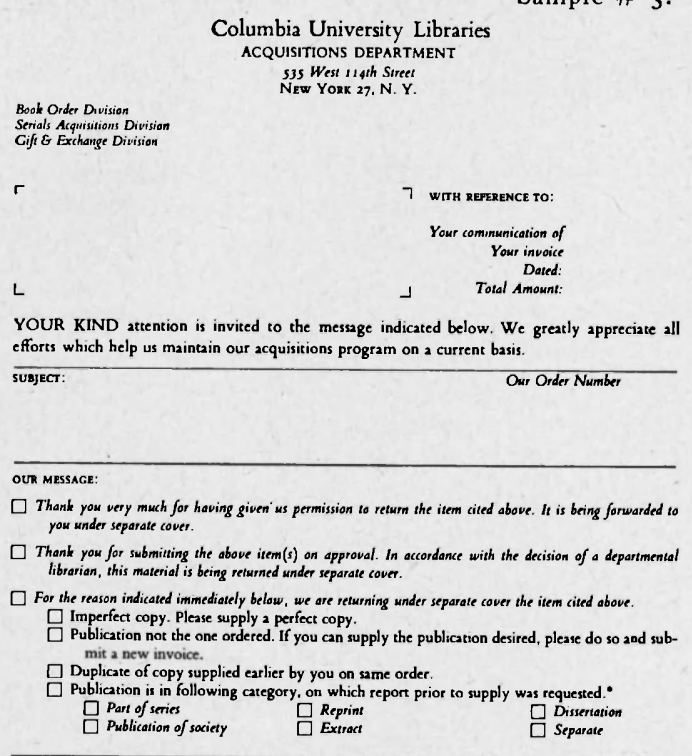

PURTHER EXPLINATION OR INSTRUCTONS:

$\square$ Payment was made for this item on your invoice as cited above. Will you, therefore, please send us a credit memorandum?

$\square$

COLUMBIA UNIVERSITY LIBRARIES Acquisitions Depantinent

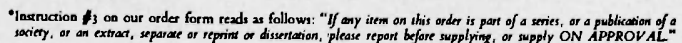

duced to a minimum; and results have been consistently satisfactory.

While at Columbia, Fleming Bennett went further in the same direction, by introducing an integrated series of seven printed form letters, two of which (see: "Sample \#2" and "Sample \#3") are essentially "claim" forms, with paragraphs or sub-paragraphs corresponding to six of the nine previously indicated- claim situations. ${ }^{1}$ Since that library, having undertaken a program of short-range, systematic claiming of overdue shipments (after four weeks, for all domestic orders, or ten weeks, for foreign orders), uses a copy of the correlated order-slip for the initial "follow-up," that first situation has not required inclusion in these letter forms. On the use of this series of form letters, Bennett ${ }^{2}$

1 Other unit-sheets in this uniformly designed series include: (I) special order situations (special delivery, on approval, etc.); (2) secondary follow-up of overdue serials items on standing- or subscription-orders; (3) solicitation of serial publication as gift or exchange; (4) other gift or exchange solicitation situations; (5) mis cellaneous correspondence form, with spaces provided for "our message" and "your reply." Window envelopes

are used with all seven.
2 In a letter to the author, dated January 14, 1952. reported: "We have found them to be great time-savers and heartily recommend their adoption for acquisitions work in libraries of your size." Prior to printing in quantity lots, the letters were tried out in mimeographed form; and some of the original messages were "revised, in the light of experience, and regrouped so as to take advantage of spacesavings afforded by letterpress."

II. Reporting, like claiming, is a generic term covering several types of operation. The three main kinds of reporting are: (I) Notification to the order-initiator of the arrival of an item-usually and most economically accomplished by return of the order-, search- or requisition-slip, endorsed with date book was received. (2) Advice to the order-initiator that the order was not placed, because item is already in the library in same or another edition. (3) Recording, and relaying to the order-initiator, of publishers' and dealers' "short reports," ("outof-print," "item sold," etc.).

Here, again, there are differences in library policy which affect fundamentally the problem of form-design. Reporting, of all three types, is important only if selection (in the sense, at least, of recommendation for purchase) is done in large part by faculty members, or a network of departmental librarians, or other "patrons" outside the order department itself or the administrative librarian. Reporting of the second sort is significant only in a library which is seriously concerned with the restriction of added-copy purchases. And reporting of the third kind may, under certain circumstances, be limited to notices of order cancellation; while, in other policy and practice conditions, a comprehensive service must be undertaken which will include the transmission of delayed-shipment reports.

This third variety of reporting is a most difficult procedure to reduce to a routine. In the first place, such reports are received in a bewildering diversity of ways: by return of the library's order-slip (or claim form) with report noted thereon, by post-card (or other printed) form, by notation on an invoice for partial shipment of total order, by added paragraph in some personal letter, etc. All of these communications must be channeled through some focal point at which the report can be noted before it gets lost in other routine procedures. 
Secondly, the report must be so expressed as to be clearly understandable both by the order-initiator and by the clerical staff of the acquisitions department, in terms of what each is expected to do about it. This is not always the case with the report-wording as received from the supplier; e.g., "not yet publishedwill be ready in May": will the book automatically be supplied in May? or must the order department reorder in May? or is the order-initiator expected to file a new request for purchase in May?

To borrow a cataloging concept for an acquisitions application, a third difficulty is that of "linearity." Just as the physical volume may cover several co-equal subjects, yet must stand in only one shelf location, so the supplier's report often covers items requested by two or more persons, yet cannot conveniently be sent to more than one, as it stands.

Finally, many short-reports require a rather intimate, professional acquaintance with the practices and proclivities of the various publishers, dealers and agents, for their intelligent interpretation. Thus, the report, "out-ofprint-we are searching," may be no more than a pious expression of good-will from one dealer, yet the promise of vigorous, effective action from another. And all too often, a report of "out-of-print" may actually mean: "We don't know where to get it or how to find out, but prefer not to admit it," or even, "We just don't care to bother with this order."

If only those reports whose effect is to cancel the order need be relayed, the problem is much less complex. If correlated order slips are used, one copy (probably the one for outstanding-order file) can be printed on the reverse side to serve as a report form, and the "pulling" of slips and the check-mark completion of the report can perhaps be done directly from the supplier's notification, however submitted. If other order- and recordforms are used, a separate $3^{\prime \prime} \times 5^{\prime \prime}$ slip, such as the University of Illinois Library form ("Sample \#4"), can be attached to the basic order record and forwarded with appropriate check-marks. This Illinois form combines compactness with exceptional flexibility: $\mathrm{By}$ the use of multiple check-marks, any variety of cancellation-report situation can be transmitted; the form can be used, not only for
"Sample \#4."

To:

\section{REPORT ON YOUR ORDER}

In Library (See back of card)

See back of this slip

See attached correspondence

Out of print

Publisher out of stock

Not yet published

Secondhand catalog order, copy sold

Reorder if continued search is desired

L80-3M-10-49-42743

Return card if added copy needed

Very scarce

Unobtainable

We are advertising

We are searching for used copy

Will supply when available

Order cancelled

University of Illinois Library-Acquisition Department

the relaying of such short-reports, but for the order-not-placed type of reporting as well, and as a sort of "buck-slip" in forwarding correspondence or reports which concern the order-initiator. The Library of Congress "Status of Order Report" combines the notification-of-arrival and the order-not-placed types of reporting with the reporting of ordercancellation situations.

If, however, organizational or policy considerations require the transmission, not only of cancellation reports, but of those shortreports whose intent is to warn of a delay in shipment ("out-of-stock," "reprinting," "importing," "new edition in preparation," "not yet published," etc.), a more complicated form and procedure is inevitable. At Cornell, where correlated order-slips are used and comprehensive relaying of short-reports is necessary, the multi-lithed, half-sheet, unit report form reproduced below serves for the transmission of both cancellation and delayin-shipment short-reports. ("Sample \#5.)" In this design, dual checking-once for reportwording and once for status-interpretation -affords adequate flexibility and the opportunity for "translation," where requisite, and leaves the recipient in no doubt as to what the acquisitions department is doing about the order.

Whether comprehensive or limited relaying of short-reports is practiced, the following principles deserve serious consideration: ( $I$ ) There should be provision for the injection of 
for:

We have received the following report on our order for the above:

Out-of-print. ___ Out-of-stock.

Agent is searching; will report.

There will be a delay in shipment of about

_.... due to reprinting; due to binding;

___ due to importation;
reason not specified.

New edition in preparation, expected in:

Item, quoted subject to prior sale, has been sold.

See attached correspondence.

Item cannot be identified; more information is required.

Other:

a modicum of professional judgment into what is essentially a clerical routine. (2) Clerical routines should be correlated with the librarian's interpretation of order-status, rather than with report-wording as received. (3) If selection is done to any large extent outside the order department, itself, reports should be specific and full, not terse and vague. (4) If the report recipient has the responsibility for decision as to further action (if any) to be taken, this should be clearly indicated.

III. Miscellaneous Correspondence. Routine correspondence with suppliers, and intercampus memoranda, offer another large area for the use of forms. Some of the many appropriate situations are:

Request for quotations (on specific item, or on desiderata list).

Notification of rejection and return of "on approval" or unsolicited shipments; (might be regarded as a "claim" situation).

Request for catalogs, and for inclusion on catalog mailing-lists.

Rejection of offer or quotation, where agent requests reply.

Transmission of catalogs to book-selectors, with instructions.

Request for permission to return an unwanted item, obtained through an error in selection, or an error in "searching."

Offer of library duplicates for sale.

\section{PRESENT STATUS OF ORDER:}

Order has been cancelled. (If you wish to have us advertise or search further, please advise.)

Awaiting future shipment.

The Library will reorder in about

Indefinite; if located,

___ item will be sent; agent will quote.

Holding, for our reply. (Please advise what action you recommend.)

Other:

\section{CORNELL UNIVERSITY LIBRARY \\ Acquisitions Department}

Cancellation of orders, solicitation of gifts and exchanges, and acknowledgment of gifts, are more obvious and common areas for the application of form-letters; and many libraries seem to employ two or more forms for some or each of these purposes.

In general, it is worth considering, as a rule-of-thumb, whether any problem in acquisitions work requiring correspondence which comes up in substantially identical form with an average frequency of once a week or more should not have a form letter (or part of one) designed to take care of it.

If it be admitted that forms have a growing importance derived from accelerating work pressures, I believe that the attention of the acquisitions librarian should be directed toward: an increase in the kinds of forms employed, wherever a new kind can serve a useful, time- and cost-reducing purpose; a decrease in the number of forms, through the consolidation of variations within the same broad class into single, multiple-purpose units; and a constant attention to the improvement of forms in the light of studied experience.

There is much help to be gained from the study of what is being done elsewhere: both in the discovery of directly-usable models for new forms or the improvement of old, and in the indirect aid of ideas which stimulate original research on problems of forms and

(Continued on page 452) 
tion of the ALA she was responsible for the organization and inspiration of many members of her profession. Her services were recognized by the grant of an honorary membership in the Division of Cataloging and Classification at the Atlantic City Conference of the ALA in 1948.
Miss Smith's influence was communicated not only through her direction of a large staff and by participation in the activities of professional groups, but also, in her earlier years, through the teaching of courses in library methods in the university.

\section{Publications}

\section{(Continued from page 443)}

the more important articles in English. The Nordisk Tidskrift för Bok och Biblioteksväsen, quarterly journal for scholarly libraries, publishes summaries in French and German as well as English, but the general library periodicals use only English. These are Biblioteksbladet (Sweden), Bog og Bibliotek (Norway), and Bogens Verden (Denmark). This new policy will greatly increase the use- fulness of these important journals, and it would be well for other library periodicals in minor languages to follow suit. The German Bücherei und Bildung inserts mimeographed English summaries with each issue, but unfortunately they are not the same size as the printed page and cannot be readily included in the bound volume.

\section{Forms in Acquisitions Work}

\section{(Continued from page 40I)}

methods. A comprehensive analysis of all the "standard brands" of forms for acquisitions work, and all their variations and permutations, would be a wonderful boon-but a staggering task to effect, since the forms, to be intelligible, must be considered in terms of services rendered and methods employed. And such a survey would require frequent revision.

Another potential boon would be some sort of current, continuous, form-review agency. -perhaps conducted as a column in a professional journal- to which sample forms would be submitted, and by which descriptive and critical comment on new developments would be disseminated. The potential usefulness of such an agency would not, of course, be restricted to acquisitions work, but might extend to formal problems of all departments of the library.

The two-year "Photo-Clerical Experi- ment," headed by Ralph Shaw ${ }^{3}$ and carried on in eleven cooperating libraries, promises to afford more objective and basic aid to the forms-designer in his problems. Even apart from the documentation the tests have produced as to the merits or ineptness of photographic methods for various routines under several sets of management conditions, this program has also arrived at some of the facts and figures on comparative cost- and performance-data of other, present methods which have heretofore been so sadly lacking. We need to know, far more clearly than we do now, what is the quickest, what is the cheapest, what is the most effective, way of accomplishing those services which are required or expected of us, in the circumstances under which we have to operate.

${ }^{3}$ Shaw, Ralph R. The Use of Photography for Clerical Routines; $\dot{A}$ Report to the American Council of Learned Societies. Washington, D.C., American Council of Learned Societies, 1953.

\section{Evans to UNESCO}

Dr. Luther H. Evans, Librarian of Congress since 1945, was elected Director General of UNESCO as of July I. A statement concerning Dr. Evans appears in the July 6, I953, issue of the LC Information Bulletin. 